\title{
Medidas de excepción previas a la justicia de transición en Colombia y sus efectos de legalidad penal: periodo $1948-1962^{1}$
}

\author{
Previous Exception Measures to the Transitional Justice in Colombia and its Effects on Criminal Legality: \\ 1948-1962
}

\author{
Rafael A. Prieto-Sanjuán ${ }^{2}$ \\ Pontificia Universidad javeriana, Colombia \\ rafael.prieto@javeriana.edu.co \\ ORCID: https://orcid.org/0000-0002-2630-3478
}

DOI: https://doi.org/10.11144/Javeriana.vj69.mepj

\author{
Jaime A. Sandoval-Mesa \\ Universidad Militar Nueva Granada, Colombia \\ jaime.sandoval@unimilitar.edu.co \\ ORCID: https://orcid.org/0000-0001-8897-4157
}

Recibido: 15 Enero 2020

Aceptado: 10 Marzo 2020

Publicado: 17 Noviembre 2020

\section{Resumen:}

El objeto del presente artículo consiste en estudiar las medidas de excepción que afectaron la legalidad penal en el período comprendido de 1948 a 1962, que para muchos constituye el punto de partida del conflicto armado en Colombia. De manera específica, se pretende analizar las fórmulas jurídicas que desde entonces fueron ejercidas para mitigar las causas de la violencia, que tarde o temprano devinieron en subversión y luego, en confluencia de diversos escenarios protagonizados por actores armados, representó la ejecución de medidas especiales que afectaron la legalidad penal, el sistema como tal y el orden constitucional vigente en dicho momento. Es decir, el sistema del Código Penal vigente en el momento (1936) y la Constitución de 1886. Lo anterior se desarrolla a partir del método hermenéutico analítico desde la visión de Arthur Kaufmann2 que considera los cuatro pilares del derecho vigente, a saber: El histórico, necesario para la descripción de las fuentes directas del período bajo examen y sus medidas; el elemento lógico y sistemático, que revela la validez del derecho vigente para la época; y, finalmente, el elemento teleológico, que resulta pertinente para verificar los elementos que sustentaban las medidas de excepción, así como también su contenido material verificable en la actualidad como lesivo de las garantías judiciales y que puede generar los cuestionamientos críticos del sistema actual y su transición desde la Constitución de 1991.

Palabras clave: Transición, medidas de excepción, legalidad penal, legitimidad, garantías judiciales, violencia política.

\section{Abstract:}

This article aims to study the exceptional measures that affected criminal legality in the period from 1948 to 1962 , which for many constitutes the starting point of the armed conflict in Colombia. Specifically, it is intended to analyze the legal formulas that have been exercised to mitigate the causes of violence, which sooner or later became subversion and then, at the confluence of various scenarios starring armed actors, represented the execution of special measures that affected the criminal legality, the system as such and the current constitutional order at that time. That is, the Penal Code system in force at the time (1936) and the Constitution of 1886. This article used the analytical hermeneutical method from Arthur Kaufmann's vision, in which he considers four pillars of current law, namely: The historical element, necessary for describing the direct sources of the period under review and its measures; the logical element and the systematic element that reveals the validity of the law in force for the time; and, finally, the teleological element, which is pertinent to verify the elements that supported the exception measures, as well as its material content that can be considered today as harmful to judicial guarantees and that can generate the critical questions of the current system and its transition since the 1991 Constitution.

Keywords: Transition, exceptional measures, criminal legality, legitimacy, judicial guarantees, first political violence.

\section{Introducción}

Como es bien sabido, durante el período de estudio (1948-1962) se presentaron formas especiales de excepción que demarcaron el concepto de justicia en los orígenes de la violencia contemporánea en Colombia.

Notas de autor

a Autor de correspondencia. Correo electrónico: rafael.prieto@javeriana.edu.co 
Medidas de excepción que afectaron el concepto de garantías judiciales, especialmente en lo relativo al principio de legalidad y al debido proceso, es decir, el sistema del código penal vigente en el momento (1936) y la Constitución de 1886. Es de destacar que, en términos de legalidad y debido proceso, la Constitución las llamaba de los Derechos Civiles y Garantías sociales (Título III, Art.23 al 28). Así, la excepcionalidad, primero prevista para momentos de excepcionalidad y luego de transición, se va a convertir en una costumbre y a extenderse hasta el momento que en que la Constitución de 1991 limitó el ejercicio de tales medidas. Sin embargo, en muchos casos, es evidente que las mismas sacrificaron garantías judiciales dado el contexto político y jurídico de la época, intrínsecamente vinculado en su elaboración promulgación y ejecución.

El objeto principal del presente artículo consiste en comprobar que, desde el período analizado (1948-1962), siempre existieron dos procesos de legalidad paralelos, uno ajustado solamente de manera formal a la Constitución y a las normas penales vigentes y otro de excepción que siempre afectó la ejecución material de las medidas penales (Código penal de 1936 y Constitución de 1886). A pesar de las diversas posiciones respecto de esta afirmación, lo cierto es que, a partir de ese momento, las declaratorias de Estado de sitio buscaban ser conjuradas mediante normas de excepción represivas, al hacer uso del mecanismo constitucional que, seguramente, se consideraban como legítimas por muchos juristas de la época.

Esta práctica ha sido frecuente y, en muchos casos, revela factores que en la actualidad son necesarios de revisión para determinar, justamente, los elementos del conflicto armado que todavía se encuentran sin resolución. Reconocer esta debilidad del Estado es importante para asegurar una visión más realista del derecho, que tiende a señalar, que no todas las medidas tuvieron un alcance legítimo y que, en el contexto de la época, sí afectaron al ciudadano y al Estado de Derecho.

En tal sentido, analizaremos las medidas judiciales adoptadas a partir de los momentos que constituyen su origen, es decir, en primer lugar, su alcance y desarrollo histórico. En esta etapa se trata de verificar el origen, desarrollo, evolución y emisión de las medidas de legalidad y excepción. En segundo lugar, su alcance jurídico, es decir, su vigencia desde la concepción lógica y sistemática del derecho, que incluye su proceso de emisión y relación con el alcance constitucional, penal e histórico del momento en que fueron emitidas. En tercer lugar, su alcance teleológico, es decir, la finalidad para la cual fueron concebidas y si, de acuerdo con tal estado del momento, resultaban o no legítimas para la sociedad y para la ejecución material de la legalidad penal ${ }^{3}$.

Desde entonces, estos dos sistemas, el penal y el constitucional, se complementan y desarrollan una protección que debe ser efectiva hacia el ciudadano desde el debido proceso y, sobre todo, desde la legalidad penal, por razón de sus límites de ejercicio. Sin embargo, para el período analizado, esta función, afectó el Estado de derecho y su legitimidad debido a los factores de excepción que serán analizados. Los factores de legalidad impresos en estas prácticas reales de excepción permitieron un sistema jurídico que no siempre fue adecuado, de allí que sea de suma importancia para la comunidad en general conocer que nuestro sistema legal, en materia penal, siempre estuvo cerca de contravenir normas internacionales de derechos humanos y del Estado de derecho.

El riesgo lo constituye que ese culto a la legalidad, heredado de las costumbres judiciales nacionales, se aparte de las nociones antropocéntricas que ahora devienen en la Constitución de 1991. Se pudo establecer que esta realidad jurídica, que tal vez escapaba a cualquier análisis de su tiempo en el campo de las autoridades judiciales, se permitía debido a la ausencia del sistema de controles jurídicos desde el terreno material en el que nos encontrábamos expuestos en ese tiempo (1948-1962). Es decir, el ciudadano se encontraba frente a factores frágiles bajo el marco de la Constitución de 1886, propio de un esquema legal débil y un sistema Constitucional ajeno a la realidad legal, que solo operaba con fines de lograr la seguridad y tranquilidad pública a toda costa por encima de los derechos de los ciudadanos.

Desde entonces se revela una preocupación, sobre todo en el área penal, pero también constitucional y de los derechos humanos por reconocer una realidad concerniente a la carencia de fundamento de muchas de estas medidas, al acudir a mecanismos formales adoptados en perjuicio de las instituciones en materia criminal. Esta línea que se va a tratar desde la legalidad penal, derechos humanos y sistema constitucional va 
a ser una constante y una necesidad susceptible de preocupación, justamente, porque solo pudo ser advertida por estas medidas de excepción. Este factor que se va a mantener hasta la actualidad con el nico límite de contención que, afortunadamente, fue propuesto por la Constitución de 1991. En términos específicos, lo anterior se revela en la afectación de la legalidad y el debido proceso, como principios que defienden los derechos de las personas sometidas a un proceso penal y también de los derechos de las víctimas actualmente.

A continuación se examinará el origen de tales circunstancias, así como los factores jurídicos que se tuvieron en cuenta para reconocer el origen de esta problemática. Cabe seala que, a pesar de que no haber cesado, por lo menos las medidas actuales se adoptan en sentido positivo y no represivo, como parte de la evolución de la justicia en un Estado de derecho, y, sobre todo, en el Estado social comprendido en la Constitución de 1991.

\section{Entre la legalidad formal y la excepcionalidad}

\section{La configuración de la legalidad penal en el origen del conflicto armado: medidas de excepción y afectación de la legitimidad}

En plena vigencia de la codificación penal de 1936 en Colombia, los hechos que causaron mayor agitación popular venían presentándose desde la década de 1930. En términos generales, se trataba de mltiples acciones populares de campesinos que respondían a los abusos de la propiedad privada. El gobierno de ese entonces promovió las primeras reformas constitucionales de tipo social, principalmente en la educación, el trabajo y la propiedad privada, las cuales trataron de encausar las demandas sociales. No obstante, el cumplimiento de dichas medidas tardó en cumplirse durante mucho tiempo, tanto así que para muchos la Ley 200 de 1936, que constituyó la primera normatividad de la reforma agraria en Colombia, no pudo implementarse en su totalidad, ni aun en la actualidad. Así, todo ello venía sembrando una crisis social que, con el devenir de la década de los aos 40, comenzaría a agudizarse, principalmente en el campo.

Además de las anteriores medidas, se suscitaron las primeras reformas penales durante la denominada Repblica Liberal en 1943, con una orientación mayor hacia la represión de ciertos delitos contra la propiedad mediante la supresión de subrogados penales y el endurecimiento de penas ${ }^{4}$. Estas medidas trataban de sofocar la crisis social y los primeros levantamientos de protesta social en Colombia. Se trató de la ley 4 de 1943, durante el segundo gobierno de Alfonso López Pumarejo. Las penas introducidas reprimían atentados contra la propiedad rural, especialmente por los conflictos que ya se hacían ver en el campo 5 .

Esta primera modificación no causó serios inconvenientes al ámbito institucional, y puede afirmarse que se trataba de cauces normales de la legislación penal[6]. Empero, en el terreno penal, este tipo de actuaciones no se reflejaban en la violencia interna del campo que tenía presupuestos paralelos de justicia de cada hacienda, pues la situación había generado el malestar de los conflictos rurales de los aos 20, 30 y 40. Algunos de esos conflictos se trataron de solucionar con la Ley 200 de 1936, aun cuando tuvo obstáculos en su ejecución.

En tal sentido, se pueden citar situaciones particulares como:

"[e]l hallazgo de matas prohibidas a los campesinos acarreaba sanciones penales en los calabozos de la hacienda, en las que se usaba el cepo y la muñequera, dos instrumentos empleados para inmovilizar a los presos, lo cual se convertía en herramientas de tortura" ${ }^{7}$.

El patrón de cada hacienda actuaba, además, como juez penal, imponiendo sanciones mediante el mecanismo de enviar al campesino incriminado con una carta (cuyo contenido ignoraba) dirigida a las autoridades, quienes al recibirla procedían penalmente contra el portador, como si el escrito del hacendado fuera formalmente una sentencia penal ${ }^{8}$.

Así, con este ejemplo de inequidad judicial en el campo, algunos observadores notan, tal vez, el inicio del periodo más oscuro de la legislación punitiva y la consecuente primera afectación grave de la legitimidad 
del sistema jurídico y, por ende, de las garantías de legalidad y enjuiciamiento penal ${ }^{9}$. Durante este periodo se desata la violencia bipartidista que tuvo, entre otros escenarios, las zonas de recientes conflictos agrarios (década del 30), influenciadas políticamente por los efímeros partidos socialistas de los años 20 del siglo pasado; por ejemplo, el Partido Comunista, que había sido fundado en 1930; la Unión de Izquierda Revolucionara (Unir), que estuvo activa entre 1933 y 1935, conducida por el dirigente popular Jorge Eliécer Gaitán, entre otras ${ }^{10}$. Fals Borda, Guzmán y Umaña Luna, señalan que, durante los años 40 , los días discurrían bajo una gran tensión política y social con marcada tendencia a la anarquía, reflejada en una creciente ola de huelgas y paros solidarios que se extendieron por todo el país desde el mes de septiembre de 1946. De tal suerte que el Ministerio de Trabajo debía conocer de más de 500 conflictos colectivos ${ }^{11}$.

En efecto, posterior a este código, en los años 40 se puede comentar que toda esa situación se agudiza con el asesinato de Jorge Eliécer Gaitán el 9 de abril de 1948, líder liberal que representaba la esperanza popular, ante los elementos de inequidad, sobre todo en el campo, que venían desde 1910. En consecuencia, el período conocido como "La Violencia", entre fuerzas políticas tradicionales en Colombia (Partido Liberal y Partido Conservador), terminaría desembocando en la dictadura del General Gustavo Rojas Pinilla, entre 1953 a $1957^{12}$.

Según Acevedo Carmona, para una gran mayoría de la población el asesinato de Gaitán y el levantamiento popular que le siguió representaron una de las mayores frustraciones del país, pues se había creado una expectativa de mejoramiento y de reforma social que implicaba un futuro promisorio. Sin embargo, el señalado episodio constituyó uno de los actos de coyuntura de una crisis que venía desde los años treinta, con el enfrentamiento entre las reformas sociales liberales y la oposición radical conservadora a su promoción efectiva, la cual se revelaba con mayor intensidad en el ambiente político de la nación y en el Congreso de la República ${ }^{13}$.

En este sentido, muchos expertos en diversas áreas coinciden en señalar que este hecho constituye el origen del conflicto armado en Colombia ${ }^{14}$, denominado como "la violencia (1948-1962) entre el Partido Liberal y el Partido Conservador" ${ }^{15}$. Allí comenzaron precisamente las medidas de estado de sitio con la consecuente afectación penal ${ }^{16}$. El historiador Herberth Braun, indicó algunos de los acontecimientos posteriores al asesinato del líder político, de la siguiente forma:

\footnotetext{
"En las dos horas y media que siguieron al asesinato de Gaitán la actividad de la multitud se diversificó y se intensificó. Al otro lado de la calle donde había caído Gaitán fue ocupada la asamblea de Cundinamarca. donde los liberales y los gaitanistas tenían mayoría. A las dos de la tarde la escena parecía un desfile con papel picado mientras los amotinados saqueaban archivos y escritorios. Papel, máquinas y muebles fueron lanzados a la calle. Se apoderaron de tranvías y de automóviles privados. los llenaron con los bienes de la gobernación y les pusieron fuego" ${ }^{17}$.
}

Con estos episodios de violencia política que venían de tiempo atrás, los principales fenómenos de crisis social se agudizaron y las medidas de excepción poco ayudaron a sofocar los serios disturbios políticos presentados frente a los cuales los instrumentos penales carecían de efectividad, lo que dio paso a la excepción punitiva. Es por ello que conviene analizar el contenido jurídico de las medidas de excepción y sus efectos en materia penal a continuación.

\section{Medidas penales de excepción en el inicio de la época de La Violencia}

Respecto de los asuntos penales, los actos derivados de la situación de Estado de Excepción desatada desde $1948^{18}$, que tuvieren como causa delitos contra el Régimen Constitucional (Rebelión) ${ }^{19}$, se desarrollaban bajo la competencia de la justicia militar y los demás en el terreno de la interpretación de la jurisdicción ordinaria $^{20}$. En el texto La violencia en Colombia, los autores destacan el siguiente relato sobre el escalamiento 
del conflicto que se presentaba en aquel tiempo. Así, seleccionamos algunos testimonios escritos de nuestro archivo particular:

\begin{abstract}
"A partir del año de 1949 la tremenda ola de barbarie que azotó esta región se estrelló contra la integridad de las personas prevalidos sus autores del amparo que las autoridades satélites del régimen de turno les brindaban. A partir de aquel año se cometió toda clase de fechorías, robos, incendios y asesinatos haciendo la vida imposible en aquel municipio. Las veredas y los campos quedaron arrasados y regados por centenares de cadáveres cuyas viudas y huérfanos no encontraron justicia. En un solo sector del municipio son sacrificados 82 varones adultos, una mujer y cuatro menores de edad"21.
\end{abstract}

Lo interesante es que, para este momento, se desarrolló la posibilidad de que la justicia militar pueda juzgar las conductas de civiles que denoten atentados contra el régimen Constitucional desde los hechos del 9 de abril. Para tal efecto, vale citar un asunto de colisión de competencias, avocado por la Sala Penal de la Corte Suprema de Justicia por hechos relacionados con un delito de homicidio en conexidad con las conductas de saqueo, robo, rebelión y asonada cometidos el 10 de abril en la población de San Vicente (Santander) ${ }^{22}$. En este caso, la Sala penal dispuso que el homicidio no era conexo con el saqueo, rebelión y asonada que constituyeron los atentados contra el Régimen Constitucional; que esto no se relacionaba con los hechos del 9 de abril y, por lo tanto, no debían ser conocidos por la justicia militar. Finalmente, la autoridad encargada del juzgamiento de tales hechos en los decretos de Estado de sitio, emitidos en tales acontecimientos, señaló que el homicidio debía ser conocido por la jurisdicción penal ordinaria ${ }^{23}$.

Por otro lado, es importante señalar que las medidas de excepción representaban asuntos de tipo constitucional $^{24}$ y tendían hacia la permanencia de los decretos especiales dictados en tal virtud. Esto, funcionaba en dos sentidos; por una parte, bajo condiciones de inhibición por la sala plena de ese entonces o por declaratorias de exequibilidad de normas que facultaban a la justicia militar para juzgar a particulares ${ }^{25}$. Sobre esto, es de destacar la decisión de sala plena de la Corte Suprema de Justicia de 10 de agosto de 1948, mediante la cual se decidió la exequibilidad de los decretos legislativos 1285 de 21 de abril y 1406 de 30 de abril de 1948, expedidos en virtud de los acontecimientos del 9 de abril, de conformidad con el artículo 121 de la Constitución de $1886^{26}$.

En estas disposiciones se definieron dos categorías de delitos que pueden ser conocidos por la justicia militar en razón del Estado de sitio. Por un lado están los delitos simples contra el régimen constitucional, la seguridad exterior, entre otros, y, por el otro, están los delitos complejos, los que además de delitos simples como el saqueo, la asonada o la rebelión sean conexos con otros delitos comunes como el homicidio, lesiones, etc. En este sentido la sentencia reiteró los efectos del artículo $7 .^{\circ}$ numerales c), d) y 22 de la ley $3 .^{a}$ de 1945 , por los delitos mencionados anteriormente ${ }^{27}$. Los mismos implicaban que aquellos hechos punibles, cometidos por los particulares en razón de un Estado de guerra, conflicto armado o de turbación del orden público y que tuvieren origen en tal situación, podían ser sometidos a los Consejos de Guerra Verbales. La Corte Suprema de Justicia determinó que los mencionados decretos eran exequibles por cuanto las normas referidas creaban la competencia y determinaban los delitos con anterioridad a las normas decretadas, debido al Estado de Sitio y por lo tanto no vulneraban el orden jurídico, ni se trataba de legislación ex post facto ${ }^{28}$.

En estos casos, la Corte Suprema de Justicia consideraba que así se salvaguardaban garantías por estar reguladas en las normas de excepción, lo que afectaba, sin duda, el principio de legalidad penal ordinario. Sobre este aspecto se puede profundizar en varias decisiones ${ }^{29}$. Por ejemplo, la decisión de la sala plena de la Corte Suprema de Justicia sobre una demanda presentada en contra del Decreto 163 de 21 de enero de 1948, expedido en virtud de los actos de turbación del orden público conforme al art. 121 de la Carta de 1886. En este caso, no solamente se hace un recuento del Estado de Sitio desde 1828 hasta 1948, sino que la Corte se declaró inhibida para declarar constitucional o inconstitucional la norma demandada, toda vez que el decreto fue dejado sin efectos por otros actos posteriores como los decretos 1239 y 1259 de 10 y 16 de abril 
de 1948. Mediante estos se declaró turbado todo el territorio, en razón de los actos del 9 de abril; y más tarde se estableció la censura de radio y prensa aplicable a todo el país mediante el decreto 1271 de 18 de abril ${ }^{30}$.

Ahora, es importante destacar que, frente a la violencia en el campo, el informe de memoria histórica de 2014 subraya que el período de violencia bipartidista fue algo más que la venganza de los terratenientes. Por un lado, los mismos no podían tener control sobre la tierra y, por el otro, se manifestaban los abusos por parte de estos con los campesinos que no tenían otra alternativa que ocupar los latifundios ${ }^{31}$.

A la par del problema en el campo, también se manifestó una crisis profunda del Estado y de sus instituciones, producida por diversas causas, múltiples objetivos y direcciones; lo que cuenta además con la participación de variados actores y grupos sociales. En ese sentido, "la violencia ejercida contra campesinos que aspiraban a cambiar sus condiciones de trabajo o a convertirse en propietarios de tierra sería una entre las distintas violencias que se manifestaron en el periodo"32.

\section{De la Violencia a la dictadura y vuelta a la democracia}

\section{Factores asociados a la excepcionalidad penal en la Dictadura y el restablecimiento de la democracia: década de los 50}

Adicionalmente a lo ya enunciado anteriormente, en los años 50 se produjeron varios acontecimientos importantes. Así, luego del retiro de las elecciones a raíz del asesinato del candidato liberal Jorge Eliécer Gaitán, resultó electo el candidato conservador Laureano Gómez para el mandato comprendido entre 1950-1954. No obstante, éste no pudo ser cumplido ya que el periodo presidencial se vio interrumpido por el golpe militar del 13 de junio de $1953^{33}$. Es de destacar que hasta esa fecha el gobierno de Laureano Gómez fue un gobierno restrictivo ${ }^{34}$. Durante su mandato, por ejemplo, presentó un proyecto de Constitución en 1950, el cual tenía agudas represiones a las libertades individuales ${ }^{35}$.

De igual forma, en materia penal, en virtud del estado de sitio y cerrado el Congreso, expidió el Decreto 957 de 1950 que aumentó en una tercera parte las penas contra el régimen constitucional y la seguridad interior del Estado, los de asociación e instigación para delinquir y de apología del delito ${ }^{36}$. Un hecho que también llamó la atención fue la criminalización del uso de radiodifusoras sin los permisos del Ministerio de Correos y Telégrafos, toda vez que en el parágrafo de la norma se señaló la represión de los demás delitos que llegaren a cometerse ${ }^{37}$.

Ese acontecimiento en particular fue muestra fehaciente de las amenazas al Estado de derecho, como lo señalan algunos ${ }^{38}$, e implicó que un régimen con motivaciones de restauración del orden conllevara a una dictadura en 1953. Esto, debido al descontento ante el supuesto gobierno democrático de 1950 a $1953^{39}$. En el fondo se trataba de medidas muy fuertes como consecuencia de la violencia desatada por El Bogotazo, pero también de medidas para reprimir la protesta social de los gobiernos posteriores ${ }^{40}$. Todo esto desconocía abiertamente la constitucionalidad y el alcance del Estado de sitio, sobre todo porque anulaba el respeto a la libertad e igualdad consagrado en las reglas aceptadas en un canon constitucional ${ }^{41}$.

Sobre la legitimidad de las medidas estatales o defensa de tales disposiciones no aparecen antecedentes oficiales más que la literalidad de su expedición ${ }^{42}$. Así, se reitera otro atentado contra la legalidad penal, en especial porque esta concepción (que repercute en la noción de legitimidad) ${ }^{43}$, por primigenia que fuese, obligaba por lo menos a conciliar la libertad, la igualdad real y participación como expresión de un Estado democrático de derecho ${ }^{44}$. De esta forma, si se suspendían garantías, debían ajustarse siquiera a los mínimos derechos de la Carta de 1886. Por supuesto, no se hizo ningún esfuerzo al respecto y menos en la 
elaboración de estas reformas penales que incluso, para ese momento, parecían encontrarse fuera de los cauces constitucionales de $1886^{45}$.

A partir del período en discusión (1948-1962) hasta la actualidad, es preciso observar el fenómeno de la legalidad penal y los problemas asociados a la legitimidad, ambos afectados por las medidas de excepción. Sobre este punto, hay que tener en cuenta que tanto legalidad como legitimidad son conceptos paralelos. Sin embargo, la legitimidad, segn Legaz y Lacambra, también posee un sentido fundamental que alude a los principios de justificación del derecho como punto de vista sobre la justicia ${ }^{46}$.

Lo anterior debido a que, a partir de estos acontecimientos, las dos situaciones van a ir por caminos separados, cada una con sus propias consecuencias, sin tener en cuenta que la legitimidad convalidaba el sistema penal y viceversa; en otras palabras, la legalidad penal permitía afirmar la legitimidad del Estado ${ }^{47}$. Esto tampoco se tuvo en cuenta para los efectos mencionados. Adicionalmente, las causas estructurales en el Estado imponían un período de crisis generador de violencia, bajo un gobierno que, para ese momento, era incapaz de resolver los conflictos a través de la conciliación y la legalidad para retornar al consenso político legitimador ${ }^{48}$.

Ahora bien, pese a que algunas de las medidas tuvieron un enfoque social ${ }^{49}$, el régimen militar creó la justicia sumaria de excepción, mediante el decreto legislativo 54 de 1954, que hacía responsable de la misma al Servicio de Inteligencia Colombiano (SIC), cuyo propósito era perseguir a los enemigos del sistema, principalmente a líderes y activistas de izquierda ${ }^{50}$. Sin lugar a duda, el Gobierno de facto desconocía la Constitución, lo cual permite afirmar que tales medidas eran ilegales y al mismo tiempo ilegítimas ${ }^{51}$. Nuevamente, se hacía caso omiso en este período del hecho que el sistema penal se encontraba gravemente afectado en su vigencia misma.

Posteriormente, cabe recordar que en los aos 60 surgieron los 2 grupos guerrilleros más importantes de Colombia (el ELN y las FARC) ${ }^{52}$ que siguen vigentes en la actualidad, abstracción hecha de ciertas disidencias o sectores que han dado el paso a la civilidad. Es importante recordar que estos grupos se originaron, precisamente, como consecuencia de movimientos sociales y grupos armados campesinos de autodefensa que habían luchado contra el régimen conservador y la dictadura militar durante La Violencia, quienes evidentemente desconfiaban del nuevo régimen ${ }^{53}$.

Desde luego, se trataba de otra sucesión de acontecimientos que implicaban la caída de la dictadura en 1957, el gobierno provisional de la junta militar de $1958^{54}$ y la instauración del denominado Frente Nacional (1958-1974), a partir del plebiscito del 1. ${ }^{\circ}$ de diciembre de 1957 que estableció la alternancia del poder de los dos partidos tradicionales para su ejercicio en todos los ámbitos estatales ${ }^{55}$.

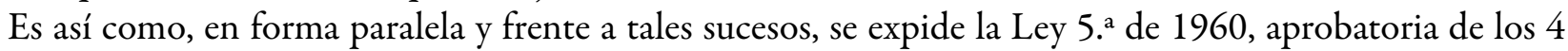
convenios de Ginebra de 1949 y, aunque no se observan trámites especiales para su entrada en vigor, este ejercicio podría dar lugar al primer ejemplo de normatividad internacional que se ocupara de escenarios de conflicto interno ${ }^{56}$. Esta legislación evidencia formas paralelas a la justicia penal vigente (Código Penal de 1936), aunque no tenía mayor significación su consagración en ese momento, dado que no se expresan situaciones o mecanismos específicos destinados a la aplicación de instrumentos internacionales en el orden jurídico nacional.

Sin embargo, en este escenario de legalidad penal y excepción, no hay que olvidar que el momento en el cual se ejecutaron tales normas, se presentaban situaciones relevantes para el desarrollo del conflicto durante los años 50 y 60 en Colombia, que tuvieron lugar con las restricciones del sistema político nacional, así como del cierre de los espacios democráticos. Desde el factor de legitimidad constitucional, esto impidió la formación de nuevos partidos o de terceras fuerzas que le permitiesen a la oposición expresarse por la vía democrática ${ }^{57}$. Lo anterior, afirma María Teresa Uribe, indujo al uso de las armas, a la insurgencia o a la violencia como forma de resistencia ${ }^{58}$. 
Así, desde los años 70 y 80 se evidencia un sistema penal insuficiente frente a un problema de conflicto armado que ya empezaba a escalar en su intensidad y afectarse por otros fenómenos de violencia que comenzaban a presentarse 59 .

\section{Los desarrollos posteriores influenciados por el período de La Violencia y la vigencia del Código Penal de 1936}

Los hechos ocurridos a partir del período de La Violencia (1948-1962) y la dictadura de Rojas Pinilla (1953-1957) se repiten durante el Frente Nacional (entre 1958-1974), para continuar con sus efectos en la figura de la justicia de excepción generadora de afectaciones al principio de legalidad, específicamente, en violaciones contra la autonomía personal ${ }^{60}$. A manera de ejemplo se pueden mencionar los decretos legislativos $4 .^{\circ}$ de 1960 y 7..$^{\circ}$ de 1961 , que les asignaron competencias a los tribunales militares para realizar juicios sumarios para juzgar a civiles. Es decir, la legalidad procesal se afectaba junto con el debido proceso que encarna la garantía judicial y que la propia Constitución de 1886 incluía en los derechos y garantías sociales (Título III Arts. 20, 23, 24, 26, 27 y 28 Constitución Política de Colombia de $1886^{61}$ ). En ellos, la policía y los militares tenían autoridad para detener a los sospechosos sin orden judicial previa, lo cual produjo un sinnúmero de abusos asociados al conflicto ${ }^{62}$.

Siguiendo este orden, se puede afirmar que los gobiernos del Frente Nacional (1958-1974) instauraron una democracia limitada, pues, como se mencionó antes, el acuerdo implicaba que solo gobernarían los dos partidos tradicionales (Liberal-Conservador), con alternancia del poder cada 4 años. Además, todo esto tenía la intención de sofocar la violencia de los recientes grupos subversivos originados en aquel entonces (FARC, ELN y M19, 1962-1970) ${ }^{63}$. Para llevar a cabo esta empresa, utilizaban la justicia de excepción que buscaba consolidar el poder de la coalición conservadora y liberal. La consecuencia fue una discutida noción de legitimidad, un desconocimiento de las garantías, de los principios democráticos de participación, y más aún, del Código Penal de $1936^{64}$.

Resulta fácil de inferir que, todo lo anterior favoreció la inestabilidad penal que se entroniza con mayor vigor en el derecho nacional de la época. Lo interesante es que, incluso para ese periodo, se tenían fundamentos claramente definidos en torno a la consideración del derecho penal del Estado de derecho, pasando por la concepción del principio de legalidad penal, hasta la configuración del delito, la determinación de la pena y el procedimiento para la fijación de ésta ${ }^{65}$. No obstante, la noción critica de su legitimidad no se discutía en ese entonces, mientras que el tratamiento jurídico de las figuras analizadas se remite a determinar el alcance de la ley penal.

En efecto, la tendencia ecléctica del código de aquel entonces, en la orientación de la escuela denominada política criminal, implicaba una discusión - todavía en desarrollo- sobre la conformación dogmática de la ley penal. Con esto, los eventos de violencia que se cernían en el país escapaban de su consideración de protección y defensa social como había sido concebido ${ }^{66}$, más aun frente a los principios penales. En este sentido, llama la atención que ya se presentaban discusiones en torno a la firmeza del principio de legalidad, pues sus fundamentos se concebían, en alguna medida, como inamovibles, incluso para algunos se consideraban acabados, tal y como lo denunciaba Romero Soto en $1969^{67}$. Lo anterior porque, desde el plano teórico, el principio de legalidad se consideraba como un pilar fundamental del sistema penal, aunque desde la actuación del ejecutivo este factor ya comenzaba a ser afectado. Lo importante es tener en cuenta que se le consideraba barrera infranqueable e ineludible de seguridad penal desde entonces ${ }^{68}$.

Todo esto era formalmente suficiente para la jurisdicción de aquel entonces, así se permitiera la convivencia del sistema penal con un sinnúmero de medidas de Estado de Excepción que, en muchos casos, eran arbitrarias a todas luces. La superación de este período tardó mucho tiempo, tal vez hasta después de 1982, e incluso 
después de la consagración de un sistema constitucional de garantías encarnado en la Constitución de 1991. Empero, al conocer las raíces de la afectación penal durante este período se puede evidenciar las difíciles condiciones en que la justicia penal tuvo que erigirse para consolidar en la actualidad una necesidad creciente de atender los contenidos materiales de la legalidad como fundamento de la legitimidad del Estado y, sobre todo, de la justicia material. Tales fundamentos pueden ser considerados como los elementos que aseguraban las garantías judiciales durante el período analizado, y que hoy no tienen discusión sobre su necesidad de respeto y protección.

\section{Conclusiones}

Desde la década de 1930, y especialmente durante los aos 40, el Código Penal y las garantías judiciales fueron insuficientes para contener las demandas que aparecían detrás de las diversas protestas sociales tanto pacíficas como aquellas que hicieron uso de la violencia. El contexto social fue superior a las posibilidades judiciales de retener la inmensa demanda de la sociedad, lo que desencadenó un periodo de anarquía que parece ser contenido en virtud de una dictadura militar. No obstante, esta dictadura tampoco fue suficiente frente a los poderes pblicos y también cede frente a las demandas de excepción penal.

En este contexto la excepcionalidad del estado de sitio en perjuicio de las competencias judiciales y la aplicación de la justicia militar a civiles constituye uno de los factores de la vulneración de las garantías judiciales. Así mismo, la legislación de tipologías penales en estas medidas también sacrifica la legalidad del código de 1936.

Como se manifestó en principio, las medidas del Estado de sitio en Colombia en el inicio de 1948 buscaban contener las diversas formas de violencia en el país bajo asuntos que apuntaban a dejar toda la responsabilidad en la justicia castrense, así tuvieren un mínimo nexo con delitos comunes y delitos contra el régimen constitucional. En este período, las formas de la justicia castrense parecían adecuadas para un Estado que se enfrentaba a una profunda crisis de anarquía institucional. Sobre todo, de legalidad formal que prevaleció sobre la materialidad de las medidas que se disponían para grandes campos desolados, donde la autoridad tenía, de lejos, una baja legitimidad.

Frente a los acontecimientos a partir de 1950 hasta 1962 se presentaron muchas medidas lesivas del Estado de derecho y de la legitimidad penal. Más aun, se presentó un régimen de democracia formal con infinidad de medidas de represión que ocasionaron un golpe de Estado militar (1953-1957). En este régimen también se adoptaron medidas de excepción que afectaban la Constitución misma.

Durante los gobiernos posteriores que fundaron un régimen denominado el Frente Nacional (1958-1974) bajo medidas de democracia limitada y alternancia del poder por los dos partidos tradicionales (Liberal y Conservador) cada cuatro aos, también se repite la costumbre de las medidas de excepción, an más frente al surgimiento de los grupos subversivos en Colombia (FARC, ELN y M19). En definitiva, es posible que muchos de estos acontecimientos ya no sean susceptibles de ser investigados o juzgados, pero sí revelan que no había consistencia en la estabilidad de las instituciones punitivas, dada la excepción mencionada.

De lo anterior se puede afirmar que no puede hablarse de solidez en los principios penales, toda vez que se introducían elementos que afectaban la legitimidad, no del derecho penal, sino del Estado mismo frente a cada fenómeno de violencia durante este tiempo. Sin embargo, en que en la actualidad pueda reconocerse que el Estado colombiano tuvo que afrontar estos períodos de indiscutibles amenazas al Estado de derecho, se deduce que no se puede sacrificar la justicia material con normas de legalidad formal en materia penal, pues se afectan los contenidos materiales de la justicia y las garantías judiciales para el ciudadano.

De igual forma, se pudo verificar que, no obstante, el hecho de que las medidas adoptadas durante el periodo bajo examen (1948-1962) resultaran lesivas de la propia legalidad y del Estado de Derecho, aun así, 
los elementos del derecho vigente las consideraban apropiadas incluso a nivel legal, es decir, consideraban legítimo su ejercicio.

Esta costumbre del ejecutivo y de las autoridades judiciales se presentó debido a la insuficiencia del derecho y del Estado del momento. En muchos casos no se tenía en cuenta el papel del derecho en el ciudadano, sino que su consagración formal era suficiente para administrar justicia. De allí que para muchos este origen de excepción, al final, propició que el cambio constitucional de 1991 sirviera de base para evitar estas prácticas que a fin de cuentas le restaron legitimidad al Estado durante el tiempo que se mantuvieron vigentes.

El hecho resulta patente en la medida en que incluso algunas produjeron medidas que se tradujeron en nuevos delitos, que en muchos casos quedaron en la impunidad, y tan sólo hasta ahora su preocupación implica reconocer las dificultades de su juzgamiento. Simplemente quedarán como aporte de memoria histórica desde la garantía de no repetición que, aun cuando puede que sólo tenga un alcance simbólico, tiene por lo menos el soporte de los procesos transicionales actuales, tanto en el foro de la ley 975 de 2005 como en el proceso de paz actual con las FARC (Acuerdo de paz de 24 de noviembre de 2016). En este terreno, la memoria histórica jurídica todavía puede ser reconstruida.

\section{Bibliografía}

1 German Guzmán Campos, Orlando Fals Borda \& Eduardo Umaña Luna, La Violencia en Colombia (Editorial Taurus, 2003).

1 Luis Enrique Romero Soto, Derecho Penal. Parte General (Editorial Temis, 1969).

Arthur Kauffman, Filosofía del Derecho (1.a ed., Editorial Universidad Externado de Colombia, 1998).

Camilo Vásquez-Cobo Carrizosa, El Frente Nacional su origen y Desarrollo (Carvajal, 1960).

Centro de Memora Histórica, Guerrilla y población civil: trayectoria de las FARC 1949-2013 (3. ed., Centro Nacional de Memoria Histórica [CNMH] y el Instituto de Estudios Políticos de la Universidad Nacional de Colombia [IEPRI], 2014).

Corte Suprema de Justicia. Sala de Casación Penal. Sentencia de 21 de mayo de 1948 (M. P. Francisco Bruno. Gaceta Judicial. Tomo LXIV. Números 2062-2063, 1948).

Corte Suprema de Justicia. Sala de Casación Penal. Sentencia de 31 de agosto de 1948 (M. P. Domingo Sarasty. Gaceta Judicial. Tomo LXIV. Números 2064-2065, 1948).

Corte Suprema de Justicia. Sala Plena. Sentencia de agosto 10 de 1948 (M. P. Domingo Sarasty Gaceta Judicial. Tomo LXV.Números 2066-2067, 1948).

Corte Suprema de Justicia. Sala Plena. Sentencia de Julio 9 de 1948 (M. P. Ramón Miranda. Gaceta Judicial. Tomo LXV. Números 2066-2067, 1948).

Daniel Pécaut, Orden y Violencia: Evolución socio-política de Colombia entre 1930 y 1953 (Editorial Grupo Editorial Norma, 2001).

Eduard Vinyamata I Camp \& Farid Samir Benavides Vanegas, El largo camino hacia la paz: Procesos e iniciativas de paz en Colombia y en Ecuador (Editorial UOC, 2011).

Grupo de Investigación Estudios sobre Identidad, Las explicaciones sobre el Conflicto Armado en Colombia, Universidad, Ciencia y Desarrollo, n. ${ }^{\circ}$ 9, 1-7 (2006). https://repository.urosario.edu.co/handle/10336/3376

Grupo de Memoria Histórica, Los orígenes, las dinámicas y el crecimiento del conflicto armado, en ¡Basta ya! Colombia: Memorias de Guerra y Dignidad (Centro Nacional de Memoria Histórica y Departamento para la prosperidad, 2014). http://www.centrodememoriahistorica.gov.co/descargas/informes2013/bastaYa/basta-ya-colombia-m emorias-de-guerra-y-dignidad-2016.pdf

Herberth Braun, Mataron a Gaitán (Fondo Editorial de la Universidad Nacional de Colombia, 1987).

Jorge Enrique Nuño Henao, Sistema penaly control social en Colombia (2002) (tesis de pregrado, Pontificia Universidad Javeriana). 
Jorge Restrepo Fontalvo, Codificaciones penales y realidad criminológica en Colombia (Universidad Santo Tomás, Centro de Investigaciones Francisco de Vitoria, 2008).

José Luis del Hierro, Legitimidady Legalidad, Eunomia: Revista en Cultura de la Legalidad, n. ${ }^{\circ} 4,179-186$ (2013). h ttps://e-revistas.uc3m.es/index.php/EUNOM/article/view/2103

Luis Carlos Sáchica, Constitución Política de Colombia. Consultada y Concordada (3. ${ }^{a}$ ed., 1990).

Luis Legaz Lacambra, Legalidad y legitimidad, Revista de Estudios Políticos, n. ${ }^{\circ}$ 101, 5-23 (1958). http://www.cepc.g ob.es/publicaciones/revistas/revistaselectronicas?IDR=3\&IDN=497\&IDA=8127

Manuel Iturralde, Castigo, liberalismo autoritario y justicia penal de excepción (Universidad de los Andes, Pontificia Universidad Javeriana, 2010).

Maria Teresa Uribe de Hincapié, Las promesas incumplidas de la democracia participativa, Seminario de Evaluación, en 1991-2001, diez años de la Constitución colombiana. Universidad Nacional de Colombia. Facultad de Derecho, Ciencias Políticas y Sociales. Instituto ILSA (2001). https://www.youtube.com/watch?v=VOBzG_WR_Ek

Marianne Moor \& Liduine Zumpolle, La Industria del Secuestro en Colombia ¿un negocio que nos concierne? (Editorial Pax Christi Holanda, 2002). https://paxencolombia.org/wp-content/uploads/2016/01/La-industri a-del-secuestro-en-Colombia.pdf

Oficina en Colombia del Alto Comisionado de las Naciones Unidas para los derechos Humanos, Compilación de Instrumentos Internacionales: Derecho Internacional de los Derechos Humanos, Derecho Internacional Humanitario y Derecho Penal Internacional (Daniel O’Donnel, Ines Margarita Uprimny \& Alejandro Valencia Villa Compiladores, 2007). https://www.hchr.org.co/index.php/publicaciones/category/48-didh-dih-dpi?download=104:compila cion-de-instrumentos-internacionales-derecho-internacional-de-los-derechos-humanos-derecho-internacional -humanitario-derecho-penal-internacional

Paul Oquist, Violencia Conflicto y Política en Colombia (Biblioteca del Banco Popular, 1978).

Revista Semana, ¿Cuándo empezó esta guerra? (14 de febrero, 2015). http://www.semana.com/nacion/articulo/cuan do-empezo-esta-guerra/417890-3

Rubén Darío Acevedo Carmona, Informe Final de Investigación proyecto: La Muerte Simbólica de Gaitán (Universidad Nacional de Colombia, Facultad de Ciencias Humanas y Económicas, 1998). http://www.bdigita l.unal.edu.co/1705/1/darioacevedocarmona.19981.pdf

\section{Notas}

1 Artículo de investigación. Financiación de la Universidad Militar Nueva Granda, Proyecto Inv. Der. Der. 2317. Las garantías judiciales en Colombia. Facultad de Derecho, Vigencia 2017.

2 Arthur Kauffman, Filosofía del Derecho, 120-125 (1.a ed., Editorial Universidad Externado de Colombia, 1998).

3 Como se mencionaba en el resumen, lo anterior obedece a la Concepción de Arthur Kaufmann desde los cuatro pilares del derecho que resultan más precisos en el campo jurídico y la teoría del derecho que otros métodos usados para análisis histórico del derecho.

4 Jorge Restrepo Fontalvo, Codificaciones penales y realidad criminológica en Colombia, 117 (Universidad Santo Tomás, Centro de Investigaciones Francisco de Vitoria, 2008).

5 Íd.

6 Centro de Memora Histórica, Guerrilla y población civil: trayectoria de las FARC 1949-2013, 36 (3.a ed., Centro Nacional de Memoria Histórica [CNMH] y el Instituto de Estudios Políticos de la Universidad Nacional de Colombia [IEPRI], 2014).

7 Íd., 36.

8 Centro de Memora Histórica, op. cit., 36.

9 Íd., 33; 1 German Guzmán Campos, Orlando Fals Borda \& Eduardo Umaña Luna, La Violencia en Colombia, 31 (Editorial Taurus, 2003).

10 Centro de Memora Histórica, op. cit., 33.

11 German Guzmán Campos, Orlando Fals Borda \& Eduardo Umaña Luna, op. cit., 31. 
12 Rubén Darío Acevedo Carmona, Informe Final de Investigación proyecto: La Muerte Simbólica de Gaitán, 3 (Universidad Nacional de Colombia, Facultad de Ciencias Humanas y Económicas, 1998).

13 Íd.

14 Eduard Vinyamata I Camp \& Farid Samir Benavides Vanegas, El largo camino hacia la paz: Procesos e iniciativas de paz en Colombia y en Ecuador, 19-20 (Editorial UOC, 2011).

15 Todos los aspectos que rodearon la muerte de Gaitán fueron tratados por Herberth Braun en Mataron a Gaitán (Fondo Editorial de la Universidad Nacional de Colombia, 1987).

16 Para ampliar la información, consultar en Grupo de Memoria Histórica, Los orígenes, las dinámicas y el crecimiento del conflicto armado, en ¡Basta ya! Colombia: Memorias de Guerra y Dignidad, 112 (Centro Nacional de Memoria Histórica y Departamento para la prosperidad, 2014).

17 Herberth Braun, op. cit., 308.

18 German Guzmán Campos, Orlando Fals Borda \& Eduardo Umaña Luna, op. cit., 43.

19 Corte Suprema de Justicia. Sala de Casación Penal. Sentencia de 31 de agosto de 1948, 878-880 (M. P. Domingo Sarasty. Gaceta Judicial. Tomo LXIV. Números 2064-2065, 1948).

20 Sobre el tema que nos interesa, es importante revisar una decisión de casación penal que dispone la no retroactividad de las normas procesales en materia penal y su vigencia inmediata, conforme a los presupuestos de la ley 153 de 1887. Reitera así mismo, por otra parte, la vigencia de la ley previa en el momento de los hechos conforme al código penal. Corte Suprema de Justicia. Sala de Casación Penal. Sentencia de 21 de mayo de 1948, 558-560 (M. P. Francisco Bruno. Gaceta Judicial. Tomo LXIV. Números 2062-2063, 1948).

21 German Guzmán Campos, Orlando Fals Borda \& Eduardo Umaña Luna, op. cit., 43.

22 Corte Suprema de Justicia. Sala de Casación Penal. Sentencia de 31 de agosto de 1948, 878-880 (M. P. Domingo Sarasty. Gaceta Judicial. Tomo LXIV. Números 2064-2065, 1948).

23 Íd.

24 Corte Suprema de Justicia. Sala Plena. Sentencia de Julio 9 de 1948, 1-16 (M. P. Ramón Miranda. Gaceta Judicial. Tomo LXV. Números 2066-2067, 1948).

25 Corte Suprema de Justicia. Sala Plena. Sentencia de agosto 10 de 1948, 17-28 (M. P. Domingo Sarasty Gaceta Judicial. Tomo LXV.Números 2066-2067, 1948).

26 Íd.

27 Íd.

28 Íd.

29 Corte Suprema de Justicia. Sala Plena. Sentencia de Julio 9 de 1948 (M. P. Ramón Miranda. Gaceta Judicial. Tomo LXV. Números 2066-2067, 1948).

30 Corte Suprema de Justicia. Sala Plena. Sentencia de Julio 9 de 1948 (M. P. Ramón Miranda. Gaceta Judicial. Tomo LXV. Números 2066-2067, 1948).

31 Centro de Memora Histórica, op. cit., 39, 42; Daniel Pécaut, Orden y Violencia: Evolución socio-política de Colombia entre 1930 y 1953, 83-88 (Editorial Grupo Editorial Norma, 2001).

32 Centro de Memora Histórica, op. cit., 42; Daniel Pécaut, Íd.

33 Este punto es relevante toda vez que el conocer el pasado de nuestro Estado como depositario legítimo del poder se adicionen elementos desconocidos en el concepto de instituciones, sobre todo penales, como las analizadas. Lo anterior, por cuanto, al revisar estos capítulos, más allá del escenario político que en la actualidad convoca el asunto, resulta oportuno precisar que expertos como los citados a la comisión especial para estudiar la propuesta de verdad de las FARC en las negociaciones de la Habana (proceso de paz 2012-2015), manifestaron que es complejo señalar el año cero de inicio del conflicto. No obstante, "Si se impone la idea de que el conflicto comenzó en los años treinta, habría que reparar a casi todo el país. Lo mismo ocurre con la justicia”. En este sentido, la revista Semana señala que "una cosa es juzgar los grandes crímenes de los años ochenta hasta la actualidad, a pensar que para que haya paz hay que resolver hasta el crimen de Jorge Eliécer Gaitán. Se puede reescribir la historia no de tres décadas sino de un siglo. Esto, advierten, es llevar al fracaso ese esfuerzo antes de que nazca”. Revista Semana, ¿Cuándo empezó esta guerra? (14 de febrero, 2015).

34 En este sentido, en el informe del centro de memoria histórica "Guerrilla y Población civil”, se manifestó que, durante el Gobierno del presidente conservador Mariano Ospina Pérez (1946-1950), el magnicidio del líder popular Jorge Eliécer Gaitán ( 9 de abril de 1948) generó un clima de frustración en amplios sectores sociales, quienes habían visto en Gaitán una figura política sensible a los intereses populares y un potencial continuador de los procesos de modernización emprendidos décadas atrás. Además, indica que la situación empeoró con el ascenso a la presidencia en 1950 del jefe conservador Laureano Gómez, debido a sus posiciones sectarias, evidentes en mecanismos como la partidización de las instituciones del Estado y las medidas represivas que aplicó contra sus contradictores políticos. Ver Centro de Memora Histórica, op. cit., 42.

35 Según el informe ¡Basta ya!”, las acciones violentas entre los partidos tradicionales, Liberal y Conservador, alcanzaron su nivel más crítico en el periodo conocido como La Violencia, que comprende desde 1946 hasta 1958. Aunque la violencia 
liberal y conservadora fue promovida por la dirigencia de ambos partidos, el enfrentamiento político se vio especialmente atizado por el sectarismo manifiesto del dirigente conservador Laureano Gómez, presidente de la República entre 1950 y 1953. A partir de entonces, el conflicto político se tradujo en una abierta confrontación armada. Grupo de Memoria Histórica, op. cit., 112.

36 Jorge Restrepo Fontalvo, op. cit., 119-120.

37 Íd., 120.

38 Según el informe Guerrilla y Población Civil, era inevitable el periodo de violencia analizado dados los argumentos de fondo que implicaban en el juicio de los líderes campesinos de la época la necesidad de una respuesta armada a un Estado que los perseguía en forma injusta y arbitraria. En este sentido el informe indica que "el malestar social se representaba en líneas generales, en que tanto liberales como comunistas esbozaron el mismo argumento de fondo: la resistencia armada contra el terrorismo de Estado. Con ello, no hicieron otra cosa que apoyarse en la legitimidad de la violencia de respuesta, fuertemente arraigada en la mentalidad colectiva de esa época, que se expresaba en el uso jurídico de la figura de la "legítima defensa", en el entendido de justificarla como una ineludible exigencia moral dirigida a neutralizar una agresión violenta, injusta y en ocasiones institucionalizada”. Centro de Memora Histórica, op. cit., 43.

39 Un aspecto que además coadyuvó al malestar social, se relaciona con la situación en el campo desde los años treinta hasta este período de los cincuenta. Para tal efecto, consultar a Daniel Pécaut quien analiza los elementos que desembocan en la violencia de los cuarenta y que incluso tienen raíces desde fines del siglo diecinueve hasta 1953. Daniel Pécaut, $o p$. cit., 83-88.

40 Jorge Restrepo Fontalvo, op. cit., 120.

41 Aunque más adelante se va a tratar el tema a profundidad, Según del Hierro, los factores mencionados de igualdad, participación y libertad son, en principio, los que otorgan legitimidad a un orden social y, a la vez, dicho orden resulta legitimado por ese respeto a estos principios emanados del Estado de derecho. José Luis del Hierro, Legitimidad y legalidad, Eunomia: Revista en Cultura de la Legalidad, n. ${ }^{\circ}$ 4, 181 (2013).

42 Para ampliar el conflicto y las medidas adoptadas en este tiempo, consultar a Paul Oquist quien, en 1978, señaló a la violencia bipartidista, motivada por el sectarismo y el afán de control del poder con exclusión del adversario como el periodo del derrumbe parcial del Estado (1946-1952), que se manifestó en la crisis e inoperancia de las instituciones establecidas, la pérdida de la legitimidad del Estado, la apelación del mismo a prácticas terroristas que debilitaron aun más la estructuración social existente, la ausencia física del Estado en grandes regiones del país y las contradicciones dentro del aparato armado del mismo. Paul Oquist, Violencia Conflicto y Política en Colombia, 255-262 (Biblioteca del Banco Popular, 1978).

43 Además de la extensa descripción de los elementos de la violencia en el período de 1948 a 1953, un aspecto que relata Paul Oquist como factor de la perdida de legitimidad del Estado se refiere al hecho de que, para ese tiempo, para millones de colombianos que vivían en cientos de municipios el gobierno era ilegítimo. Se presentaba una resistencia pasiva y armada de los liberales frente a la represión oficial dondequiera que no se acataba la autoridad del Gobierno. Todo esto desembocó en grupos enfrentados e incluso organizados denominados grupos de contraguerrilla conservadores, apoyados por las autoridades del gobierno y el poder judicial, que dejó como consecuencia la disminución del poder del Estado. Paul Oquist, op. cit., 256-257.

44 José Luis del Hierro, op. cit., 181.

45 Para hacer una síntesis del momento, el informe “¡Basta ya!” señala los siguientes elementos de esta primera violencia: "El hecho de que los miembros del aparato burocrático estatal, del sistema de justicia y de las Fuerzas Armadas estuvieran afiliados a uno de los dos partidos tradicionales, aunque la Constitución ordenaba que los uniformados debían ser apolíticos, fue uno de los generadores de altos niveles de violencia. A ello se sumó la intervención de la Iglesia católica a favor del partido Conservador, hecho que le dio una justificación moral y religiosa al discurso antiliberal y anticomunista. La Violencia se expresó contra los movimientos agrarios, obreros y populares urbanos aglutinados en torno a los ideales del gaitanismo. Alcanzó su máximo nivel de radicalización política tras el asesinato del líder liberal Jorge Eliécer Gaitán, el 9 de abril de 1948, suceso que desató protestas populares y fue conocido como El Bogotazo. En la década de 1950, la violencia se libró entre los ciudadanos adscritos a ambas colectividades políticas mediante el ataque a los militantes del partido contrario o a sus territorios de influencia. Dentro de los partidos políticos se constituyeron agrupaciones armadas con diferentes niveles de organización: de un lado, la policía chulavita . Los pájaros (asesinos a sueldo), al servicio del Gobierno Conservador; del otro, las guerrillas liberales y las autodefensas comunistas”. Grupo de Memoria Histórica, op. cit., 112.

46 Luis Legaz Lacambra, Legalidad y legitimidad, Revista de Estudios Políticos, n. ${ }^{\circ}$ 101, 8 (1958).

47 La forma de legitimidad, según Legaz Lacambra, es la creencia en la legalidad, o sea, la obediencia a preceptos jurídicos positivos estatuidos según el procedimiento usual y formalmente correctos. Íd., 9.

48 Sobre el particular, la Comisión de Estudios Sobre la Violencia, creada por el gobierno de Belisario Betancourt en 1987, a cargo del Instituto de Estudios Políticos y Relaciones Internacionales (IEPRI) de la Universidad Nacional, determinó que, con distintos lenguajes y fines políticos, la sociedad colombiana asumió que la violencia desatada en los 
años cincuenta tuvo causas estructurales generadas por la exclusión social y la desigualdad económica. Sobre esto, había consenso en cuanto a la explicación del nacimiento y la consolidación de movimientos insurgentes como consecuencia de esa condición. Grupo de Investigación Estudios sobre Identidad, Las explicaciones sobre el Conflicto Armado en Colombia, Universidad, Ciencia y Desarrollo, n. ${ }^{\circ}$, 1-7 (2006).

49 Se puede citar, en primer lugar, el acto legislativo n. 3 de 1954 que otorgó derechos políticos a la mujer y que solo pudieron ser ejercidos por primera vez en el plebiscito de 1957. En segundo lugar, se puede citar el Decreto 534 del 19 de febrero de 1954 sobre la defensa de las pesas, calidades y medidas, por medio de la cual se tipificaron conductas como la venta de artículos de primera necesidad, dañados, alterados o adulterados. Ver Jorge Restrepo Fontalvo, op. cit., 121.

50 Manuel Iturralde, Castigo, liberalismo autoritario y justicia penal de excepción, 60 (Universidad de los Andes, Pontificia Universidad Javeriana, 2010).

51 En este tiempo aparecen algunas referencias sobre las normas de excepción como los Decretos de estado de sitio, entre ellos: el Decreto 434 del 1. ${ }^{\circ}$ de marzo de 1956 con base en el acto legislativo del mismo año que prohibió las actividades de comunismo internacional; el decreto 0014 del 12 de enero de 1955 que se aplicó a personas cuyos antecedentes, actividades, hábitos o formas de vivir, las colocasen en estado de peligrosidad social (derogado por el decreto 1699 del 16 de julio de 1964). Así mismo, se puede citar el decreto 250 del 11 de julio de 1958 (Código Penal Militar). Los anteriores decretos fueron declarados como legislación permanente mediante ley 141 del 16 de diciembre de 1961 . Ver Jorge Enrique Nuño Henao, Sistema penal y control social en Colombia, 39 (2002) (tesis de pregrado, Pontificia Universidad Javeriana).

52 En un comienzo, los grupos guerrilleros se afianzaron firmemente en los grupos de resistencia campesina, originados a finales de la década de los cuarenta. En relación con los grupos subversivos, el grupo base de las FARC se originó en 1964 y desde su formación contó con el apoyo de la antigua Unión Soviética; mientras que el ELN recibió ayuda de la Revolución Cubana, principalmente durante el período de la Guerra Fría. Se menciona que durante este periodo "La Habana" ayudó a este grupo en la capacitación, organización y entrenamiento de sus miembros, lo que produjo un crecimiento relativo hasta 1973, año en que las acciones militares casi ocasionaron su exterminio. Marianne Moor \& Liduine Zumpolle, La Industria del Secuestro en Colombia ¿un negocio que nos concierne?, 21 (Editorial Pax Christi Holanda, 2002).

53 Precisamente algunos campesinos, integrantes de estos grupos, escaparon durante la ofensiva militar del Presidente del Frente Nacional, Guillermo León Valencia (1962-1966), para luego conformar lo que sería la semilla de las FARC. Manuel Iturralde, op. cit., 62.

54 El 10 de mayo de 1957 el General Rojas Pinilla se apartó del poder y se marchó al exilio. En su lugar se conformó la Junta Militar Provisional, precedida por el Mayor General Gabriel Paris Gordillo, el Mayor General Deogracias Fonseca Espinosa, el Contralmirante Rubén Piedrahita Arango, el Brigadier General Rafael Navas Pardo y el Brigadier General Luis E. Ordóñez Castillo. Durante este régimen se expidió el Decreto 236 de 1957, que modificó el delito de fuga de presos y agravó las sanciones previstas del artículo 203, negando la posibilidad de excarcelación para dicha conducta. Jorge Restrepo Fontalvo, op. cit., 123.

55 Uno de los documentos interesantes sobre la creación del Frente Nacional se tejió en Benidorm, el viernes 20 de julio de 1956, en el sitio denominado el Peñón de Ifach (Cataluña, España). Según las memorias de Camilo Vasquez-Cobo Carrizosa, en uno de los apartes el mencionado testigo presencial de los acuerdos logrados se refiere al encuentro que sostuvo el Dr. Gómez, al comentar lo siguiente: "Por la tarde en mi entrevista de hoy a la cual asistía la hija del Expresidente, quien debe recordarla muy bien, el Dr. Gómez me habló sobre posibilidades en caso de caída de la Dictadura. 'Tenemos el compromiso de los liberales... El candidato conservador'. La respuesta del Dr. Gómez volvió a contemplar la caída de Rojas y su reemplazo. Es un tema que nos ha planteado varias veces comenzando con la pregunta: 'Cómo puede caerse Rojas'. -Pero hoy llevó la divagación más allá de suponer que la caída se produjese por acción de los partidos y de los militares... 'que queda, ¿que sigue...?’ De la Constituyente ni hablar. Supuso entonces el Dr. Gómez que las circunstancias no darían margen sino para que una junta se encargase transitoriamente del gobierno”. Camilo Vásquez-Cobo Carrizosa, El Frente Nacional su origen y Desarrollo, 154-155 (Carvajal, 1960).

56 Se indica que la ley 5. a de 1960 permitió la entrada en vigencia de los 4 convenios citados - y por ende, del artículo 3 común a los mismo- el 8 de mayo de 1962. Oficina en Colombia del Alto Comisionado de las Naciones Unidas para los derechos Humanos, Compilación de Instrumentos Internacionales: Derecho Internacional de los Derechos Humanos, Derecho Internacional Humanitario y Derecho Penal Internacional, 381 (Daniel O’Donnel, Ines Margarita Uprimny \& Alejandro Valencia Villa Compiladores, 2007).

57 La autora señala que esta exclusión social no se agotaba en los marcos de la política, sino que, a su vez, se presentaba en formas que afectaban a las etnias dominadas que tenían que ver, de manera muy contundente, con las asimetrías en las relaciones institucionales de las regiones y las localidades con el centro administrativo del Estado. Maria Teresa Uribe de Hincapié, Las promesas incumplidas de la democracia participativa, Seminario de Evaluación, en 1991-2001, diez años de la Constitución colombiana. Universidad Nacional de Colombia. Facultad de Derecho, Ciencias Políticas y Sociales. Instituto ILSA, 146 (2001). 
59 Según María Teresa Uribe, el centralismo daría lugar a muchos de los conflictos bélicos posteriores (años 70 y 80), al dejar territorios y pueblos sin presencia institucional de la fuerza pública, y al margen de los programas de desarrollo y bienestar social. Íd.,146.

60 Manuel Iturralde, op. cit., 60.

61 Luis Carlos Sáchica, Constitución Política de Colombia. Consultada y Concordada, 38-51 (3.a ed., 1990).

62 Íd., 60.

63 Eduard Vinyamata I Camp \& Farid Samir Benavides Vanegas, op. cit., 20. En el mismo sentido, ver Marianne Moor \& Liduine Zumpolle, op. cit., 21.

64 Manuel Iturralde, op. cit., 62. Así, se podría afirmar que los problemas actuales de esta relación entre legitimidad y legalidad penal ocuparon desde entonces a tres codificaciones penales, es decir, el Estatuto del 36 citado, el decreto ley 100 de 1980 y el código actual de 2000 (ley 599).

651 Luis Enrique Romero Soto, Derecho Penal. Parte General, 38 y 178 (Editorial Temis, 1969).

66 Todavía a finales de los sesenta, Romero Soto definía el Código de 1936 de la siguiente forma: "Si de la escuela positiva toma la defensa social como criterio básico, lo templa con el concepto de equidad, profundamente clásico. Si de aquella presta la denominación de sanciones, vuelve en cambio el rostro al clasicismo al dividirlas en penas, término que rechaza el positivismo y medidas de seguridad con la cuales se denomina esta última escuela. Se declara la actividad sicofísica como fundamento de la imputabilidad, pero al mismo tiempo se declara no culpables a los que han obrado a quienes actúen bajo error, coacción o sugestión hipnótica, etc. También fija límites máximo y mínimo de las penas (Dosimetría penal)". En general se puede entender para ese tiempo de Política Criminal como tesis intermedia. Luis Enrique Romero Soto, op. cit., 172 y 173.

67 Luis Enrique Romero Soto, op. cit., 178.

68 En suma, de los principios enunciados se analizan las consecuencias como la prohibición de retroactividad de la ley penal, la prohibición de la analogía, la inadmisibilidad de la costumbre como fuente de derecho penal y la imposibilidad de que un reglamento contenga normas penales. Íd., 178.

\section{Licencia Creative Commons CC BY 4.0}

Para citar este artículo/To cite this article: Rafael A. Prieto-Sanjuán \& Jaime A. Sandoval-Mesa, Medidas de excepción previas a la justicia de transición en Colombia y sus efectos de legalidad penal. periodo 1948-1962, 69 Vniversitas (2020). https://doi.org//10.11144/Javeriana.vj69.mepj 